\title{
Influence of Different Kinds of Plant Fibers on the Curing Kinetics of Epoxy Resin
}

\author{
Yeng-Fong Shih ${ }^{1}$, Jia-Yi Xu ${ }^{1}$, Nian-Yi Wu ${ }^{1}$, Ting-Yuan $\mathrm{Ou}^{1}$, and Saprini Hamdiani ${ }^{1,2^{*}}$ \\ ${ }^{1}$ Department of Applied Chemistry, Chaoyang University of Technology, No. 168, Jifeng E. Rd., \\ Wufeng District, Taichung 41349, Taiwan \\ ${ }^{2}$ Department of Chemistry, Faculty of Mathematics and Natural Sciences, University of Mataram, \\ Majapahit Street No. 62, NTB 83115, Indonesia
}

* Corresponding author:

tel: $+886-973068465$

email:saprini.h@unram.ac.id

Received: June 18, 2021

Accepted: November 19, 2021

DOI: $10.22146 / \mathrm{ijc} .66771$

\begin{abstract}
The curing kinetics of the epoxy resin crosslinked by an anhydride hardener with and without plant fibers was investigated. The epoxy composites containing modified pineapple leaf fiber (EASF), banana fiber (EBSF), and bamboo chopsticks fibers (ECSF) were analyzed by non-isothermal differential scanning calorimetry (DSC) technique. Dynamic methods were used to predict the total heat of reaction of the epoxy resin and its activation energy based on the methods of Kissinger and Ozawa. The results showed that, at a low heating rate $\left(5^{\circ} \mathrm{C} / \mathrm{min}\right)$, the $\triangle H$ of the pure epoxy, EASF, EBSF, and ECSF were 326.2, 307.6, 295.6, and $366.6 \mathrm{~J} / \mathrm{g}$, respectively. The curing rate increased, and the activation energy was decreased due to the catalytic role of hydroxyl groups of plant fibers. Based on Kissinger and Ozawa methods, the calculation of activation energy for pure epoxy was $70.08 \mathrm{~kJ} / \mathrm{mol}$ and $73.21 \mathrm{~kJ} / \mathrm{mol}$, EBSF was $68.07 \mathrm{~kJ} / \mathrm{mol}$ and $71.41 \mathrm{~kJ} / \mathrm{mol}$, ECSF was $60.11 \mathrm{~kJ} / \mathrm{mol}$ and $63.87 \mathrm{~kJ} / \mathrm{mol}$, and EASF was $58.71 \mathrm{~kJ} / \mathrm{mol}$ and $62.49 \mathrm{~kJ} / \mathrm{mol}$. The activation energy for the three kinds of epoxy composite modified fibers was less than pure epoxy resin due to the gel effect resulting from the higher viscosity, faster curing rate, and steric hindrance.
\end{abstract}

Keywords: epoxy; curing kinetics; plant fiber; activation energy

\section{- INTRODUCTION}

Epoxy resin can be cured at room or elevated temperature by adding hardeners, resulting in a threedimensional structure. After cross-linking, epoxy resin is a thermoset polymer, with some different characteristics from the general resin, such as low volume shrinkage, dimensional stability, superior mechanical properties, excellent chemical resistance, corrosion resistance, thermal stability, good electrical insulation, and other excellent properties. Therefore, epoxy resin is widely used in electronic components substrates, structural adhesives, composite materials, the aviation industry, sports equipment, and military engineering [1].

Recently, plant fibers have replaced glass fibers and are widely used to reinforce polymers concerning environmental aspects. The advantages of plant fibers over glass fibers include low density, low cost, recyclability, and biodegradability [2-4]. Many researchers have investigated the reinforcing effects on the plant fiberreinforced epoxy and various polymer composites [5-9]. Sapuan et al. (2006) used woven banana fibers, water bamboo husk, palm fiber, fruit bunches/jute fibers, and untreated Phormium Tenax leaf fibers. The addition of woven banana fibers to Musaceae/epoxy resulted in the composite with the maximum stress of $26.181 \mathrm{MN} / \mathrm{m}^{2}$ and Young's modulus of $2.685 \mathrm{GN} / \mathrm{m}^{2}$ [5]. Bamboo husk increased the storage moduli of PLA 50-200\% [6]. Palm fiber added to the polyester resin increased the composite's interfacial relaxation strength $(\Delta \varepsilon)$ to 85.743 at $130{ }^{\circ} \mathrm{C}$ [7]. Oil palm empty fruit bunches (EFB)/jute fiber reinforced the epoxy hybrid composite's flexural properties. The flexural strength and modulus of jute/EFB/jute were $49.0 \mathrm{MPa}$ and $3.07 \mathrm{GPa}$, respectively, higher than the pure epoxy, which was $33.5 \mathrm{MPa}$ and $1.04 \mathrm{GPa}$ [8]. In the research proposed by Rosa et al. (2010), the use of untreated Phormium Tenax leaf fibers 
to epoxy composites showed the increment of modulus and strength both in tensile and flexural loading compared to pure epoxy resin [9]. Many researchers discuss the reinforcement effect of plant fiber. However, only a few kinds of literature explained the reaction kinetics of epoxy resin [10-11].

Achilias et al. [12] performed isothermal scanning by differential scanning calorimetry (DSC) and observed the curing reaction between the epoxy resin and the cycloaliphatic diamine. They obtained the relationship between the hardening temperature and the reaction order. In addition, they found that the results analyzed by Fourier Transform Infrared (FT-IR) spectroscopy were consistent with those by DSC. Yeo [13] used DSC to investigate the curing behavior and obtain the reaction rate constant and reaction activation energy of liquid crystalline 4,4'-diglycidyloxybiphenyl epoxy with various diamines. Ren et al. [14] studied the curing kinetics of the epoxy resin hardened by phthalide-containing aromatic diamine. They calculated the reaction activation energy of epoxy resins with different structures through a secondary self-catalytic reaction mechanism. The results showed that the increased rigidity of the chain and reduced symmetry would increase the activation energy of the curing reaction. Bessa et al. [10] extracted Arundo donax L. cellulosic fibers (RF) from giant reed cane and investigated the effect of raw and treated RF on the curing kinetics of bisphenol A-based benzoxazine (BA-a) by DSC technique under non-isothermal conditions. RF was subjected to different chemical treatments, including alkaline, silane, or combining treatments. The results revealed a decrease in the heat of curing and activation energy $(\mathrm{Ea})$.

In this study, three kinds of agricultural wastes (pineapple leaf fibers, banana fibers, and bamboo chopsticks fibers) [15-18] were incorporated into epoxy resin to prepare the plant fiber-reinforced epoxy composites. The waste was found in a huge abundant agricultural waste in Taiwan. Every year more than 5 million tons of waste is produced. Plant waste can be a severe problem and pollute the environment. Such waste requires proper treatment to increase its commercial utilization. In addition, the influence of different plant fibers on the curing kinetics of epoxy resin was investigated by the non-isothermal DSC technique. Ozawa [19-21] and Kissinger [22-24] methods were used to predict the curing behavior of the epoxy resin. The kinetic studies are critical to provide general information, especially if a large industrial-scale composite will be manufactured. The kinetic prediction can reduce the process, cost, and time-consuming in commercialization.

\section{- EXPERIMENTAL SECTION}

\section{Materials}

Bisphenol F-epoxy resin (ML3564) with a density of $1.1 \mathrm{~g} / \mathrm{cm}^{3}$, polyaminoanhydride (curing agent), and benzyldimethylamine (accelerator) were supplied by Golden-Gate Chem. Co., Taiwan. Silane coupling agent (3-aminopropyltriethoxysilane) (Sigma Aldrich) was supplied by Dow Corning Co. The banana plant and pineapple leaves were kindly supplied by Taiwan Agricultural Research Institute.

\section{Instrumentation}

Polarizing optical microscopy (POM) (Carl Zeiss, Axio Scope A1) was used to analyze the morphology of fibers. The curing behavior was analyzed by a differential scanning calorimeter (TA Instruments DSC Q20).

\section{Procedure}

\section{Fibers treatment and preparation of composites}

The raw pineapple leaf fiber (ASF), banana fiber (BSF), and recycled disposable chopsticks fibers (CSF) were alkaline treated, washed with distilled water, and dried in an oven. The fibers were then chopped and screened to obtain an average length of 2 to $4 \mathrm{~mm}$, and subsequently treated by a silane coupling agent (3aminopropyltriethoxysilane) (Fig. 1) to obtain the modified pineapple leaf fiber, banana fiber, and recycled disposable chopsticks fiber. Next, the epoxy, curing agent, accelerator (100:90:2), and different kinds of modified fibers (20 wt.\%) were mixed to obtain the modified fiber-reinforced epoxy composites (EASF, EBSF, and ECSF). The composites sample with a mass of 5-10 mg was kept in a sealed aluminum pan in DSC equipment. The heating program was set to $30-250{ }^{\circ} \mathrm{C}$ 
at different heating rates of $5,10,15$, and $20^{\circ} \mathrm{C} / \mathrm{min}$ under a constant nitrogen atmosphere.

\section{Kinetic analysis}

The degree of curing reaction (or cross-linking conversion rate), $\alpha$, can be calculated by using the concentration of epoxy before and after the reaction or the change in the heat of the reaction as follow [25-27]:

$\alpha=\frac{[E]_{\mathrm{o}}-[\mathrm{E}]_{\mathrm{t}}}{[\mathrm{E}]_{\mathrm{O}}}$

or $\alpha=\frac{\mathrm{H}_{\mathrm{t}}}{\Delta \mathrm{H}}$

where $[E]_{o}$ and $[E]_{t}$ are the concentrations of epoxide at the beginning of curing and after curing time $t$, respectively. $\mathrm{H}_{\mathrm{t}}$ is the enthalpy at a determined time and temperature, whereas $\Delta \mathrm{H}$ is the total enthalpy of the curing reaction. The reaction rate equation for epoxy curing reactions can be expressed as:

$\frac{\mathrm{d} \alpha}{\mathrm{dt}}=\mathrm{kf}(\alpha)$

or $g(\alpha)=\int \frac{d \alpha}{f(\alpha)}=\int k d t$

where $\alpha$ is the conversion of epoxy, $\mathrm{k}$ is the total reaction rate constant, and $f(\alpha)$ is the function of conversion rate, which is related to the reaction mechanism. The Arrhenius equation can be described as the relationship between reaction rate constant $\mathrm{k}$ and temperature T. A, $\mathrm{Ea}$, and $\mathrm{R}$ are the pre-exponential factor, the activation energy, and the universal gas constant, respectively.

$\mathrm{k}=\mathrm{A} \exp ^{(-\mathrm{Ea} / \mathrm{RT})}$

There are two methods to study the kinetics of the curing reaction of epoxy resin by DSC: dynamic method and isothermal method (or static method). The dynamic method is used to record the relationship between the heat change of the reaction and the temperature at a fixed heating rate. The isothermal method is used to carry out the curing reaction at a fixed temperature and record the reaction heat versus time curve. The results obtained by the DSC measurement can be analyzed by Ozawa Method [19-21], Kissinger Method [22-24], or Barrett Method [28] to calculate the kinetic parameters such as total reaction rate constant, frequency factor, total reaction order, and reaction activation energy.
Kissinger method [22]. Assuming that the curing conversion is a function of time and temperature, the reaction rate $(r)$ of the curing reaction can be expressed as:

$\mathrm{r}=\frac{\mathrm{d} \alpha}{\mathrm{dt}}=\left(\frac{\partial \alpha}{\partial \mathrm{t}}\right)_{\mathrm{T}}+\left(\frac{\partial \alpha}{\partial \mathrm{T}}\right)_{\mathrm{t}} \frac{\mathrm{dT}}{\mathrm{dt}}$

When the reaction is a first-order reaction, and the temperature is fixed, $\mathrm{dT} / \mathrm{dt}=0$, so the above formula can be rewritten as:

$\frac{\mathrm{d} \alpha}{\mathrm{dt}}=\mathrm{k}(1-\alpha)$

When the reaction rate reaches the maximum at the peak temperature $T_{p}$, the differential value of the reaction rate concerning time $\frac{\mathrm{d}}{\mathrm{dt}}\left(\frac{\mathrm{d} \alpha}{\mathrm{dt}}\right)$ is zero. Substituting the Arrhenius equation in Eq.7 and letting the heating rate $\mathrm{dT} / \mathrm{dt}=\beta$, the following equation can be obtained:

$-\ln \left(\frac{\beta}{\mathrm{T}_{\mathrm{p}}^{2}}\right)=-\ln \left(\frac{\mathrm{AR}}{\mathrm{E}_{\mathrm{a}}}\right)+\frac{\mathrm{E}_{\mathrm{a}}}{\mathrm{RT}_{\mathrm{p}}}$

By plotting $\ln \left(\frac{\beta}{T_{p}^{2}}\right)$ versus $1 / T_{p}$, the activation energy $\left(E_{a}\right)$ and the frequency factor (A) can be obtained from the slope and the intercept.

Ozawa method [19-21,29]. Different integration methods for Eq. (3) can be used. One example is the Ozawa method. Flynn and Wall [30] and Ozawa [1921,29] have shown that at a constant degree of conversion, the activation energy of a reaction is related to the heating rate, $\beta$, and the peak temperature of the reaction, $\mathrm{T}_{\mathrm{p}}$, by the following equation:

$\mathrm{E}_{\mathrm{a}}=\frac{-\mathrm{R}}{1.052} \frac{\Delta \ln \beta}{\Delta\left(1 / \mathrm{T}_{\mathrm{p}}\right)}$

where $\mathrm{R}$ is the ideal gas constant $(8.314 \mathrm{~J} / \mathrm{mol} \mathrm{K})$. The activation energy can be estimated from the slope of the plot of $\ln \beta$ versus $1 / T_{p}$.

\section{- RESULTS AND DISCUSSION}

\section{Synthesis of Modified Fibers-Crosslinked Epoxy Composites}

The synthesis process of modified fibers began with the delignification process. Delignification for 
pineapple, banana, and recycled disposable chopsticks fibers in alkaline conditions aims to remove lignin and hemicellulose content. The removal of lignin and hemicellulose will improve the performance and surface properties of the fibers [31-33]. The chemical composition of pineapple, banana, and recycled disposable chopsticks fibers is $\sim 98.63 \%$ cellulose [34-36]. Cellulose contained a hydroxyl group that will react with -Si-O- groups in 3-aminopropyltriethoxysilane to produce modified fibers. The formation of modified fibers will increase the stability of the epoxy composite [37-38]. Thus, the amine groups in modified fibers provide free electrons by nucleophilic addition process to open the oxirane rings in epoxy. The reaction forced the curing reaction process. An illustration of the curing reaction of the epoxy resin and modified fiber (MF) is shown in Fig. 1.

\section{Morphology of Fibers}

Fig. 2(a), (b), and (c) showed the morphology of modified pineapple leaf fiber, banana fiber, and recycled disposable chopsticks fiber analyzed by polarized optical microscopy (POM). The diameters of modified pineapple leaf fiber, banana fiber, and recycled disposable chopsticks fiber were about 50, 30, and $60 \mu \mathrm{m}$, respectively. The difference in diameter of the modified fibers affects the composite's physical properties, which affects the curing process's heat $(\Delta \mathrm{H})$ and activation energy. Sivasubramanian et al. (2020) used pineapple leaf fiber with diameters of 50,100, and $150 \mu \mathrm{m}$ as natural rubber composites fillers [39]. Researchers found that fibers with a diameter of more than $100 \mu \mathrm{m}$ will decrease filler distribution in the composite. The filler function will be practical if the filler fibers fragment into smaller sizes, which will increase their distribution in the composite [39-40]. In this study, the diameter of the fiber less than $100 \mu \mathrm{m}$ would be better to improve the physical properties of the composite. The effect of fiber diameter on the curing process will be explained in the kinetics analysis.

\section{Kinetics Analysis}

DSC thermograms of pure epoxy and the composites containing modified pineapple leaf, banana, or recycled disposable chopsticks fiber (EASF, EBSF, and ECSF) at a different heating rate $(5,10,15$, and $20{ }^{\circ} \mathrm{C} / \mathrm{min}$ ) are shown in Fig. 3-6. It is found that the

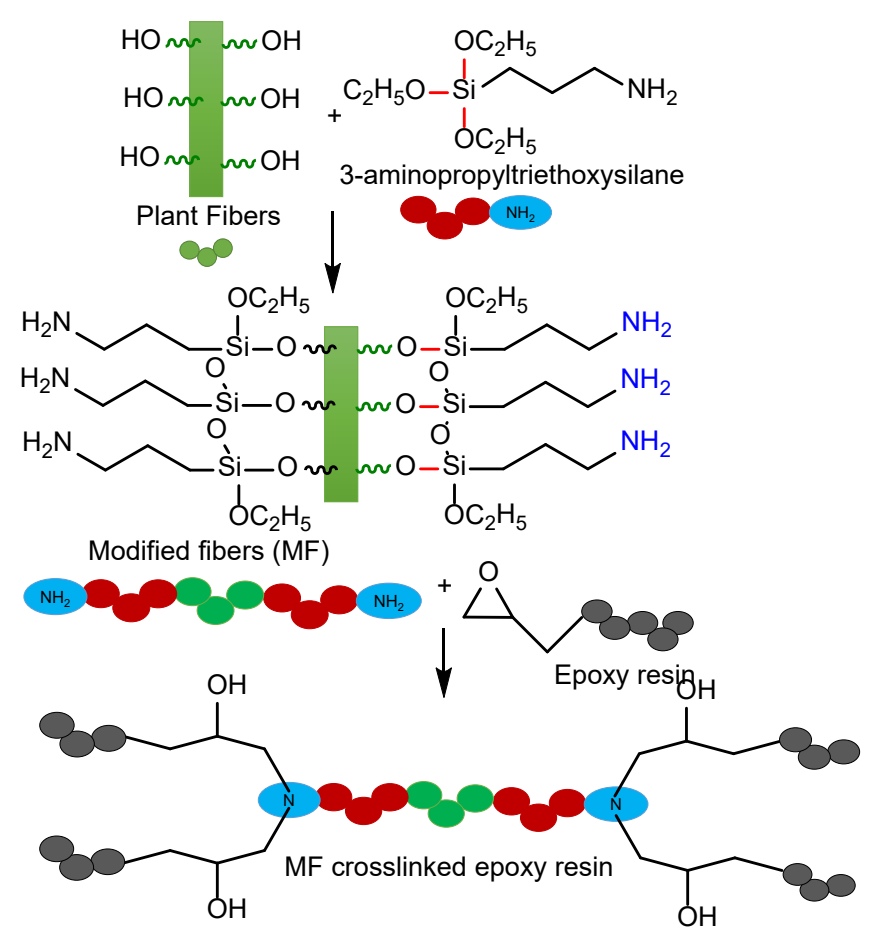

Fig 1. Illustration of curing reaction of the epoxy resin and modified fiber (MF)

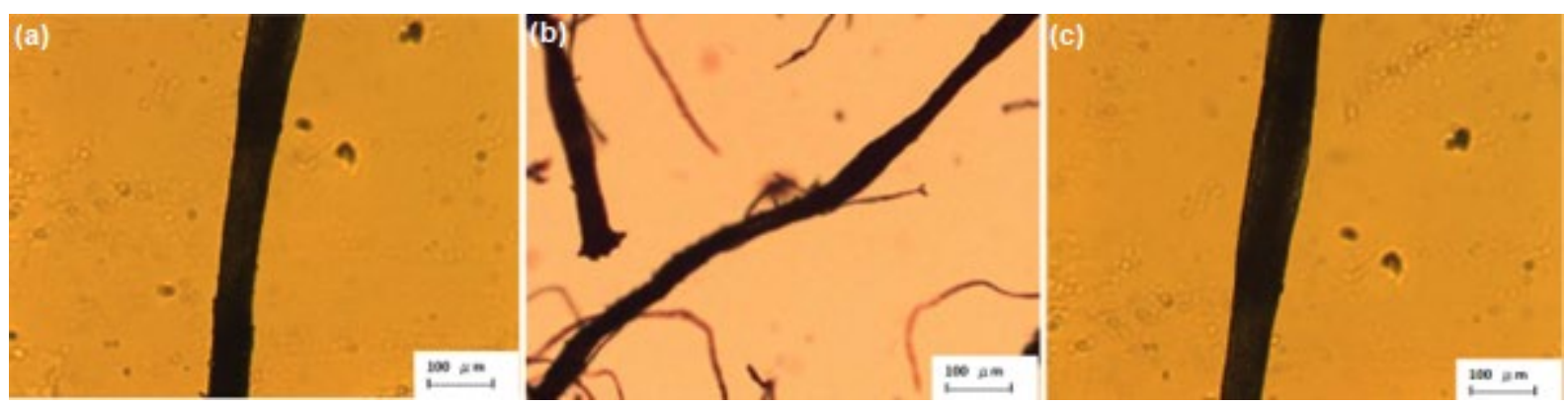

Fig 2. POM micrographs of (a) ASF (b) BSF (c) CSF 


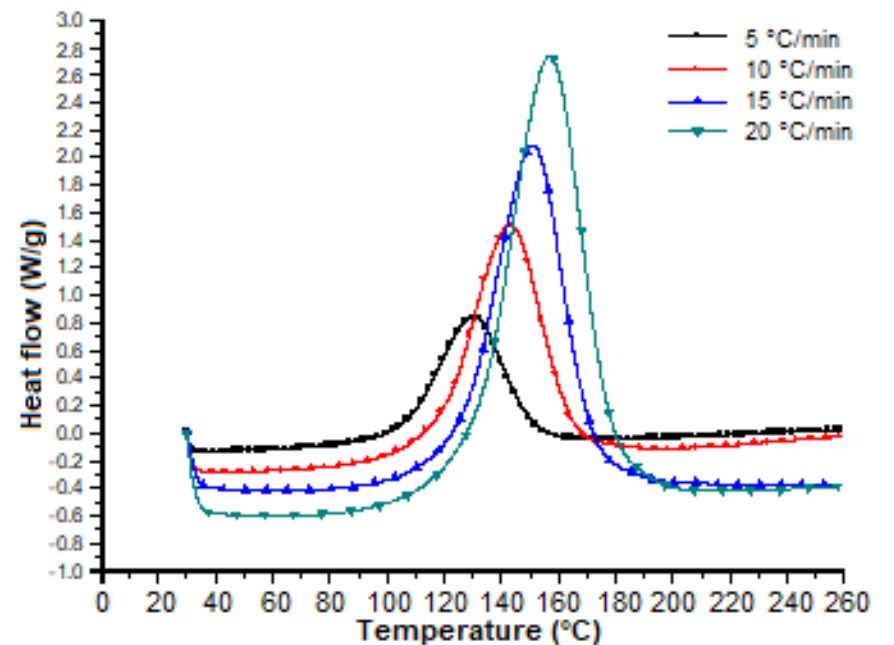

Fig 3. DSC thermograms of pure epoxy at a different heating rate

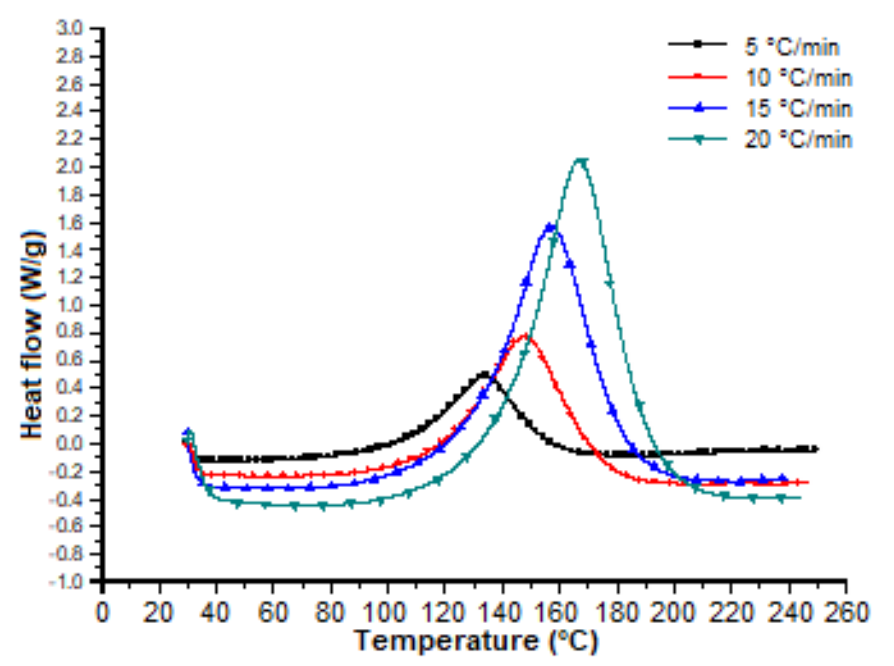

Fig 5. DSC thermograms of EBSF composite at a different heating rate

initial curing temperature $\left(\mathrm{T}_{\mathrm{i}}\right)$ and the peak temperature $\left(T_{p}\right)$ were all increased with the increasing heating rate. In addition, the exothermic peak was getting sharper with the increasing heating rate. The results of DSC analysis, including heating rate $(\beta)$, initial curing temperature $\left(T_{i}\right)$, peak temperature $\left(T_{p}\right)$, final curing temperature $\left(T_{f}\right)$, and the heat of curing $(\Delta \mathrm{H})$, are shown in Table 1 .

The degree of crosslinking of epoxy can be evaluated by the heat of curing $(\Delta \mathrm{H})$. The results showed that the $\Delta \mathrm{H}(307.6$ and $295.6 \mathrm{~J} / \mathrm{g})$ of the EASF and EBSF at a low heating rate $\left(5^{\circ} \mathrm{C} / \mathrm{min}\right)$ was smaller than that of pure epoxy $(326.2 \mathrm{~J} / \mathrm{g})$. It is speculated that the smaller diameter of

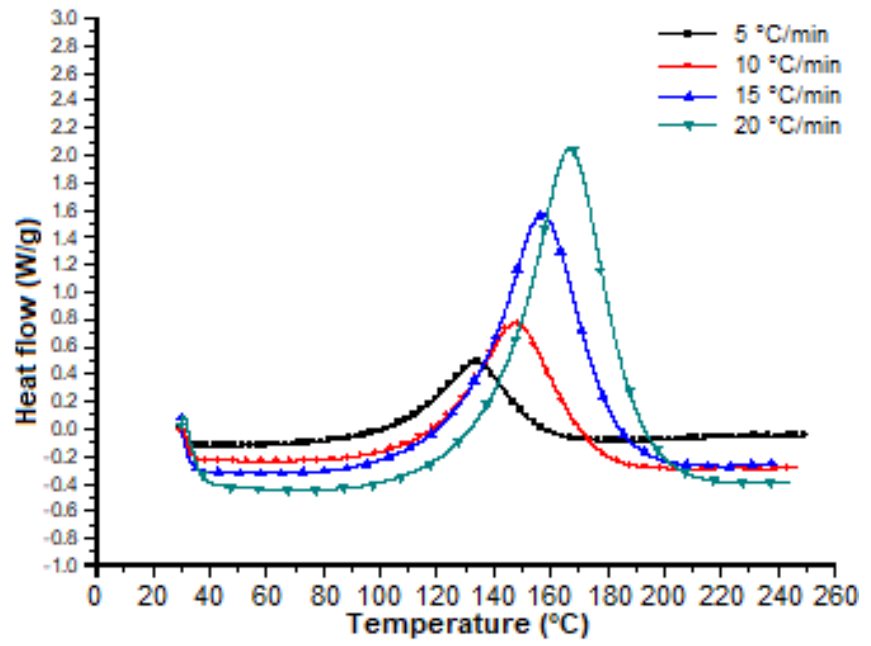

Fig 4. DSC thermograms of EASF composite at a different heating rate

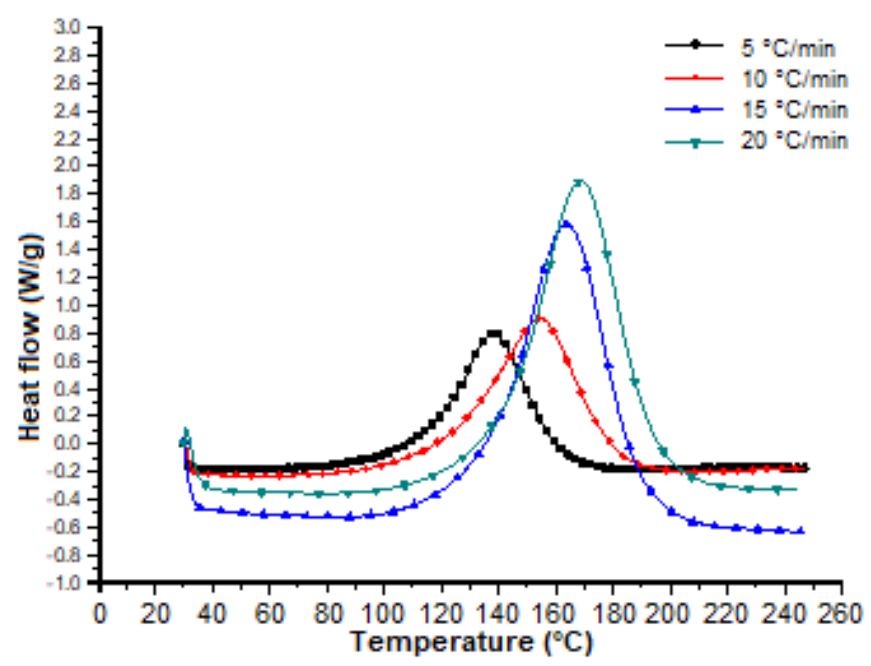

Fig 6. DSC thermograms of ECSF composite at a different heating rate

modified pineapple leaf fiber and banana fiber makes its volume fraction larger, which leads to higher viscosity and steric hindrance. The fibers with smaller diameters contained a considerable amount of particles. The increase of particle density thus hinders the curing process cause of the higher viscosity. In the banana fibers, the fiber diameter is only $50-60 \%$ of the other two fibers, so its volume fraction is substantial, leading to a higher viscosity and steric hindrance. Therefore, its heat of curing $(\Delta \mathrm{H})$ is the smallest, which means that the degree of crosslinking is low. The illustration of the fibers particle density in the composites system is shown in Fig. 7. 


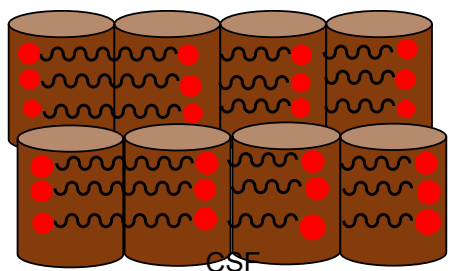

(a)

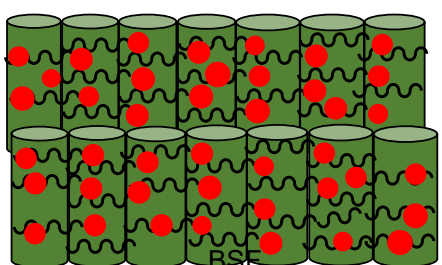

(b)

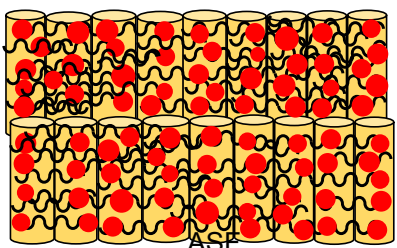

(c)

on $-\mathrm{OH}$ groups

Fig 7. The illustration of fibers with different diameter sizes and the appearance of hydroxyl groups on the surface

Table 1. The results of DSC analysis

\begin{tabular}{|c|c|c|c|c|c|}
\hline Sample & $\begin{array}{c}\mathrm{B} \\
\left({ }^{\circ} \mathrm{C} / \mathrm{min}\right)\end{array}$ & $\begin{array}{c}\mathrm{T}_{\mathrm{i}} \\
\left({ }^{\circ} \mathrm{C}\right)\end{array}$ & $\begin{array}{c}\mathrm{T}_{\mathrm{p}} \\
\left({ }^{\circ} \mathrm{C}\right)\end{array}$ & $\begin{array}{c}\mathrm{T}_{\mathrm{f}} \\
\left({ }^{\circ} \mathrm{C}\right)\end{array}$ & $\begin{array}{c}\Delta \mathrm{H} \\
(\mathrm{J} / \mathrm{g})\end{array}$ \\
\hline \multirow[t]{4}{*}{ Pure epoxy } & 5 & 42.6 & 131.1 & 176.9 & 326.2 \\
\hline & 10 & 55.4 & 143.2 & 190.1 & 313.1 \\
\hline & 15 & 73.5 & 151.4 & 215.7 & 314.8 \\
\hline & 20 & 76.7 & 157.1 & 217.2 & 321.2 \\
\hline \multirow[t]{4}{*}{ EASF } & 5 & 50.1 & 134.7 & 180.9 & 307.6 \\
\hline & 10 & 68.7 & 148.1 & 204.9 & 335.0 \\
\hline & 15 & 78.0 & 157.3 & 215.1 & 352.8 \\
\hline & 20 & 87.4 & 166.7 & 220.1 & 340.8 \\
\hline \multirow[t]{4}{*}{ EBSF } & 5 & 44.7 & 138.6 & 182.4 & 295.6 \\
\hline & 10 & 53.0 & 152.8 & 205.8 & 311.6 \\
\hline & 15 & 73.4 & 160.8 & 211.4 & 324.3 \\
\hline & 20 & 87.9 & 166.1 & 215.6 & 290.3 \\
\hline \multirow[t]{4}{*}{ ECSF } & 5 & 56.6 & 138.6 & 184.8 & 366.6 \\
\hline & 10 & 68.1 & 154.6 & 210.3 & 333.4 \\
\hline & 15 & 87.1 & 164.4 & 232.2 & 328.6 \\
\hline & 20 & 89.4 & 169.1 & 233.1 & 318.9 \\
\hline
\end{tabular}

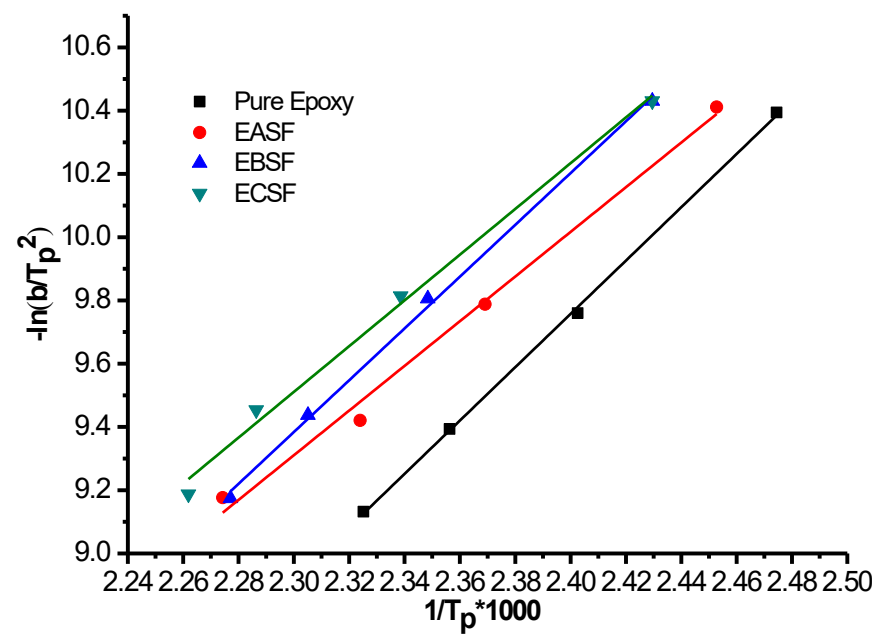

Fig 8. Analysis diagram of pure epoxy resin and composites drawn in Kissinger model
At the same time, the results of DSC analysis were used to calculate the reaction activation energy of pure epoxy resin and three kinds of fiber-reinforced composites through Kissinger and Ozawa methods. After importing from the formula, the analysis diagram of pure epoxy resin and various composites drawn in the Kissinger model is obtained and shown in Fig. 8, while the analysis diagram of pure epoxy resin and various composites in the Ozawa model is shown in Fig. 9. In addition, the activation energy and linear regression values obtained are sorted as shown in Table 2. It was found that the linear regression values were all larger than 0.993, indicating that both models were appropriate for describing the curing reactions, and the predicted curves from the calculated kinetic parameters fit well with the experimental data.

The results in Table 2 show that the order of activation energy is pure epoxy (Kissinger: $70.08 \mathrm{~kJ} / \mathrm{mol}$,

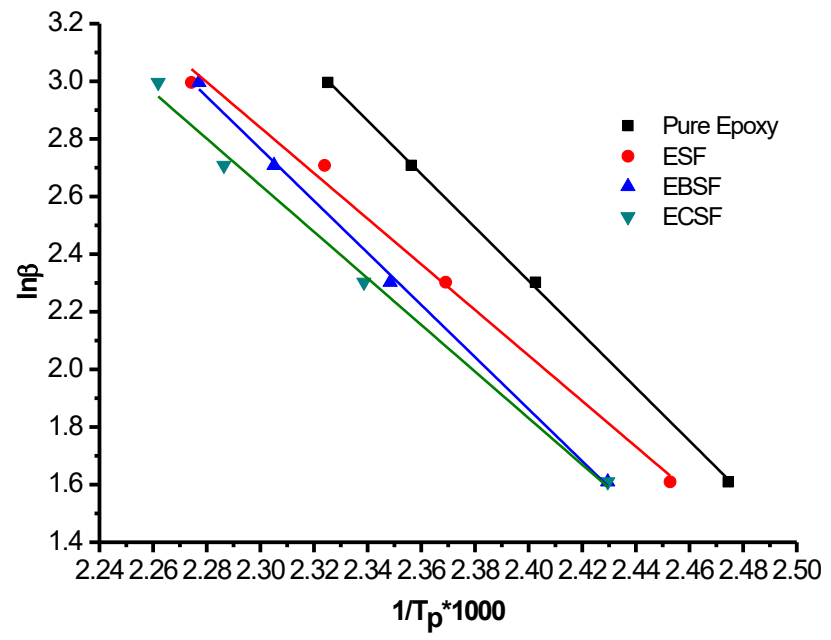

Fig 9. Analysis diagram of pure epoxy resin and composites drawn in Ozawa model 
Table 2. Activation energy and regression value obtained by Kissinger and Ozawa model

\begin{tabular}{lcccc}
\hline Sample & \multicolumn{2}{c}{ Kissinger method } & \multicolumn{2}{c}{ Ozawa method } \\
\cline { 2 - 5 } & $\mathrm{E}_{\mathrm{a}}(\mathrm{kJ} / \mathrm{mol})$ & Regression & $\mathrm{E}_{\mathrm{a}}(\mathrm{kJ} / \mathrm{mol})$ & Regression \\
\hline Pure epoxy & 70.08 & 0.999 & 73.21 & 0.999 \\
EASF & 58.71 & 0.993 & 62.49 & 0.994 \\
EBSF & 68.07 & 0.998 & 71.41 & 0.999 \\
ECSF & 60.11 & 0.995 & 63.87 & 0.996 \\
\hline
\end{tabular}

Table 3. Comparison of activation energy value with similar studies of other systems

\begin{tabular}{|c|c|c|c|}
\hline Type of polymer & Type of reinforced materials/fibers & $\mathrm{E}_{\mathrm{a}}(\mathrm{kJ} / \mathrm{mol})$ & Ref. \\
\hline Bisphenol A-based & - No fibers & 95.81 & [10] \\
\hline \multirow[t]{3}{*}{ benzoxazine } & - Giant reed cellulosic fibers (Arundo donax L/AF) alkali-treated & 95.09 & \\
\hline & - AF silane treated & 86.42 & \\
\hline & - AF alkali silane treated & 88.19 & \\
\hline \multirow[t]{2}{*}{ Epoxy } & - No fibers & 72.63 & [11] \\
\hline & - Curauá fibers alkaline treated & 61.57 & \\
\hline Bisphenol & - No fibers & 58.97 & [41] \\
\hline $\begin{array}{l}\text { A/triethylenetetramine } \\
\text { (DGEBA/TETA) epoxy }\end{array}$ & - $20 \% \mathrm{v}$ Mallow fibers & 44.54 & \\
\hline \multirow{3}{*}{$\begin{array}{l}\text { Bisphenol A (BPA)-based } \\
\text { epoxy }\end{array}$} & - No fibers & 48.40 & {$[42]$} \\
\hline & - $25 \%$ de-polymerized Kraft/organosolv lignins (softwood) & 48.30 & \\
\hline & - $25 \%$ de-polymerized Kraft/organosolv lignins (hardwood) & 45.10 & \\
\hline
\end{tabular}

Ozawa: $73.21 \mathrm{~kJ} / \mathrm{mol}$ ) > EBSF (Kissinger: $68.07 \mathrm{~kJ} / \mathrm{mol}$, Ozawa: $71.41 \mathrm{~kJ} / \mathrm{mol}$ ) > ECSF (Kissinger: $60.11 \mathrm{~kJ} / \mathrm{mol}$, Ozawa: $63.87 \mathrm{~kJ} / \mathrm{mol}$ ) > EASF (Kissinger: $58.71 \mathrm{~kJ} / \mathrm{mol}$, Ozawa: $62.49 \mathrm{~kJ} / \mathrm{mol}$ ). These results reveal that the activation energy required for the reaction of the three kinds of fiber-reinforced composites is less than that of pure epoxy resin. Presumably, the hydroxyl groups on the fiber surface can promote the reaction. Moreover, the amine groups on the surface of the modified fiber will also participate in the reaction, thus accelerating the curing reaction. It can be found that the activation energy of the composite containing modified banana fiber (EBSF) is larger than those of the other two composites. Banana fibers have the smallest diameters with the highest activation energy value. As explained previously, the fibers with smaller diameters contained a huge particle density. The massive fiber density contained more hydroxyl groups on the banana fiber surface than the other fiber. Although the hydroxyl groups promote the curing reaction, in this case, too crowded hydroxyl groups on the surface cause the increment of steric hindrance in banana leaf (BSF) fibers (see Fig. 7). This result is consistent with that obtained from heat of curing. It is due to that the diameter of the modified banana fiber is small so that its volume fraction is larger, resulting in a larger viscosity and stereoscopic barriers, and leads to the larger activation energy. Our results were in good agreement with the previously reported work [10-11,4143], where the value of activation energy decreases by the addition of fibers/modified fibers, as summarized in Table 3.

\section{- CONCLUSION}

The results showed that the hydroxyl groups on the plant fiber and the amine groups on the modified fiber could accelerate the cross-linking reaction and reduce the activation energy of the epoxy resin. The calculation by Kissinger and Ozawa method showed the reduction of activation energy was $2.8 \%$ and $2.4 \%, 14.2 \%$ and $12.8 \%$, and $16.2 \%$ and $14.6 \%$ for EBSF, ECSF, and EASF, respectively. However, the final degree of cross-linking for pure epoxy resin was more significant than the composites containing fibers. This is because the higher viscosity of the composite and the accelerating effects of 
the hydroxyl groups on the plant fiber and amine groups on the modified fiber resulted in greater viscosity and steric hindrance, leading to the lower final degree of crosslinking. EASF and ECSF have a similar degree of crosslinking and activation energy among the three fibercontaining composites. The degree of cross-linking of EBSF is the lowest due to the smallest diameter of banana fiber, leading to a large volume fraction, higher viscosity, and steric hindrance so that the degree of cross-linking is relatively tiny with great activation energy.

\section{- AUTHOR CONTRIBUTIONS}

Author Contributions: Y.F. Shih conceived and designed the original idea and methodology; Y.F. Shih, J.Y. Xu, and N.Y. Wu fabricated the sample, data collection, and curation; Y.F. Shih prepared the original draft; T.Y. Ou revised the draft; S. Hamdiani wrote the review and editing. All authors have read and agreed to the published version of the manuscript.

\section{- REFERENCES}

[1] Saba, N., Jawaid, M., Alothman, O.Y., Paridah, M., and Hassan, A., 2016, Recent advances in epoxy resin, natural fiber-reinforced epoxy composites and their applications, J. Reinf. Plast. Compos., 35 (6), 447-470.

[2] Kumar, R., Kumar, K., Sahoo, P., and Bhowmik, S., 2014, Study of mechanical properties of wood dust reinforced epoxy composite, Procedia Mater. Sci., 6, 551-556.

[3] Rohit, K., and Dixit, S., 2016, A review - Future aspect of natural fiber reinforced composite, Polym. Renewable Resour., 7 (2), 43-59.

[4] Mahmud, S., Hasan, K.M.F., Jahid, M.A., Mohiuddin, K., Zhang, R., and Zhu, J., 2021, Comprehensive review on plant fiber-reinforced polymeric biocomposites, J. Mater. Sci., 56 (12), 7231-7264.

[5] Sapuan, S.M., Leenie, A., Harimi, M., and Beng, Y.K., 2006, Mechanical properties of woven banana fibre reinforced epoxy composites, Mater. Des., 27 (8), 689-693.

[6] Wang, K.H., Wu, T.M., Shih, Y.F., and Huang, C.M., 2008, Water bamboo husk reinforced poly(lactic acid) green composites, Polym. Eng. Sci., 48 (9), 1833-1839.

[7] Amor, I.B., Ghallabi, Z., Kaddami, H., Raihane, M., Arous, M., and Kallel, A., 2010, Experimental study of relaxation process in unidirectional (epoxy/palm tree fiber) composite, J. Mol. Liq., 154 (2-3), 61-68.

[8] Jawaid, M., Abdul Khalil, H.P.S., and Abu Bakar, A., 2010, Mechanical performance of oil palm empty fruit bunches/jute fibres reinforced epoxy hybrid composites, Mater. Sci. Eng., A, 527 (29-30), 79447949.

[9] De Rosa, I.M., Santulli, C., and Sarasini, F., 2010, Mechanical and thermal characterization of epoxy composites reinforced with random and quasiunidirectional untreated Phormium tenax leaf fibers, Mater. Des., 31 (5), 2397-2405.

[10] Bessa, W., Trache, D., Derradji, M., Ambar, H., Tarchoun, A.F., Benziane, M., and Guedouar, B., 2020, Characterization of raw and treated Arundo donax L. cellulosic fibers and their effect on the curing kinetics of bisphenol A-based benzoxazine, Int. J. Biol. Macromol., 164, 2931-2943.

[11] Libera, V.D., Teixeira, L.A., Leão, R.M., and Luz, S.M., 2019, Evaluation of thermal behavior and cure kinetics of a curauá fiber prepreg by the nonisothermal method, Mater. Today: Proc., 8, 839-846.

[12] Achilias, D.S., Karabela, M.M., Varkopoulou, E.A., and Sideridou, I.D., 2012, Cure kinetics study of two epoxy systems with Fourier transform infrared spectroscopy (FTIR) and differential scanning calorimetry (DSC), J. Macromol. Sci., Part A: Pure Appl. Chem., 49 (8), 630-638.

[13] Yeo, H., 2019, Curing kinetics of liquid crystalline 4,4'-diglycidyloxybiphenyl epoxy with various diamines, Polymer, 168, 209-217.

[14] Ren, R., Xiong, X., Ma, X., Liu, S., Wang, J., Chen, P., and Zeng, Y., 2016, Isothermal curing kinetics and mechanism of DGEBA epoxy resin with phthalide-containing aromatic diamine, Thermochim. Acta, 623, 15-21.

[15] Shih, Y.F., Cai, J.X., Kuan, C.S., and Hsieh, C.F., 2012, Plant fibers and wasted fiber/epoxy green composites, Composites, Part B, 43 (7), 2817-2821. 
[16] Boopalan, M., Niranjanaa, M., and Umapathy, M.J., 2013, Study on the mechanical properties and thermal properties of jute and banana fiber reinforced epoxy hybrid composites, Composites, Part B, 51, 54-57.

[17] Jain, J., Jain, S., and Sinha, S., 2019, Characterization and thermal kinetic analysis of pineapple leaf fibers and their reinforcement in epoxy, J. Elastomers Plast., 51 (3), 224-243.

[18] Shih, Y.F., Chang, W.C., Liu, W.C., Lee, C.C., Kuan, C.S., and Yu, Y.H., 2014, Pineapple leaf/recycled disposable chopstick hybrid fiber-reinforced biodegradable composites, J. Taiwan Inst. Chem. Eng., 45 (4), 2039-2046.

[19] Ozawa, T., 1971, Kinetics of non-isothermal crystallization, Polymer, 12 (3), 150-158.

[20] Zheng, T., Xi, H., Wang, Z., Zhang, X., Wang, Y., Qiao, Y., Wang, P., Li, Q., Li, Z., Ji, C., and Wang, X., 2020, The curing kinetics and mechanical properties of epoxy resin composites reinforced by PEEK microparticles, Polym. Test., 91, 106781.

[21] Kumar, S., Samal, S.K., Mohanty, S., and Nayak, S.K., 2017, Study of curing kinetics of anhydride cured petroleum-based (DGEBA) epoxy resin and renewable resource based epoxidized soybean oil (ESO) systems catalyzed by 2-methylimidazole, Thermochim. Acta, 654, 112-120.

[22] Kissinger, H.E., 1956, Variation of peak temperature with heating rate in differential thermal analysis, $J$. Res. Nat. Bur. Stand., 57 (4), 217-221.

[23] Ferdosian, F., Zhang, Y., Yuan, Z., Anderson, M., and $\mathrm{Xu}$, C.C., 2016, Curing kinetics and mechanical properties of bio-based epoxy composites comprising lignin-based epoxy resins, Eur. Polym. J., 82, 153-165.

[24] Tikhani, F., Moghari, S., Jouyandeh, M., Laoutid, F., Vahabi, H., Saeb, M.R., and Dubois, P., 2020, Curing kinetics and thermal stability of epoxy composites containing newly obtained nano-scale aluminum hypophosphite $\left(\mathrm{AlPO}_{2}\right)$, Polymers, 12 (3), 644.

[25] Saeb, M.R., Rastin, H., Nonahal, M., Ghaffari, M., Jannesari, A., and Formela, K., 2017, Cure kinetics of epoxy/MWCNTs nanocomposites: Nonisothermal calorimetric and rheokinetic techniques, J. Appl. Polym. Sci., 134 (35), 45221.

[26] Wu, F., Zhou, X., and Yu, X., 2018, Reaction mechanism, cure behavior and properties of a multifunctional epoxy resin, TGDDM, with latent curing agent dicyandiamide, RSC Adv., 8 (15), 8248-8258.

[27] Thanki, J.D., and Parsania, P.H., 2017, Dynamic DSC curing kinetics and thermogravimetric study of epoxy resin of 9,9'-bis(4-hydroxyphenyl) anthrone-10, J. Therm. Anal. Calorim., 130 (3), 2145-2156.

[28] Barrett, K.E.J., 1967, Determination of rates of thermal decomposition of polymerization initiators with a differential scanning calorimeter, J. Appl. Polym. Sci., 11 (4), 1617-1626.

[29] Tripathi, M., Kumar, D., Rajagopal, C., and Roy, P.K., 2015, Curing kinetics of self-healing epoxy thermosets, J. Therm. Anal. Calorim., 119 (1), 547555.

[30] Flynn, J.H., and Wall, L.A., 1966, A quick, direct method for the determination of activation energy from thermogravimetric data, J. Polym. Sci., Part B: Polym. Lett., 4 (5), 323-328.

[31] Buitrago, B., Jaramillo, F., and Gómez, M., 2015, Some properties of natural fibers (sisal, pineapple, and banana) in comparison to man-made technical fibers (aramide, glass, carbon), J. Nat. Fibers, 12 (4), 357-367.

[32] Sari, N.H., Wardana, I.N.G., Irawan, Y.S., and Siswanto, E., 2018, Characterization of the chemical, physical, and mechanical properties of $\mathrm{NaOH}$-treated natural cellulosic fibers from corn husks, J. Nat. Fibers, 15 (4), 545-558.

[33] Wahyuningsih, K., Iriani, E.S., and Fahma, F., 2016, Utilization of cellulose from pineapple leaf fibers as nanofiller in polyvinyl alcohol-based film, Indones. J. Chem., 16 (2), 181-189.

[34] Asim, M., Abdan, K., Jawaid, M., Nasir, M., Dashtizadeh, Z., Ishak, M.R., and Hoque, M.E., 2015, A review on pineapple leaves fibre and its composites, Int. J. Polym. Sci., 2015, 950567. 
[35] Radoor, S., Karayil, J., Rangappa, S.M., Siengchin, S., and Parameswaranpillai, J., 2020, A review on the extraction of pineapple, sisal and abaca fibers and their use as reinforcement in polymer matrix, eXPRESS Polym. Lett., 14 (4), 309-335.

[36] Padam, B.S., Tin, H.S., Chye, F.Y., and Abdullah, M.I., 2014, Banana by-products: An under-utilized renewable food biomass with great potential, J. Food Sci. Technol., 51 (12), 3527-3545.

[37] Lu, T., Jiang, M., Jiang, Z., Hui, D., Wang, Z., and Zhou, Z., 2013, Effect of surface modification of bamboo cellulose fibers on mechanical properties of cellulose/epoxy composites, Composites, Part B, 51, 28-34.

[38] Parbin, S., Waghmare, N.K., Singh, S.K., and Khan, S., 2019, Mechanical properties of natural fiber reinforced epoxy composites: A review, Procedia Comput. Sci., 152, 375-379.

[39] Sivasubramanian, P., Mayandi, K., Santulli, C., Alavudeen, A., and Rajini, N., 2020, Effect of fiber length on curing and mechanical behavior of pineapple leaf fiber (PALF) reinforced natural rubber composites, J. Nat. Fibers, 0 (0), 1-12.

[40] Chandra Sekhar, V., Sreedhar, C., and Rajesh, P., 2018, Effect of fiber loading and fiber length on tensile properties of fiber reinforced epoxy composites, Mater. Today: Proc., 5 (13), 27149-27154.

[41] Nascimento, L.F.C., da Luz, F.S., Costa, U.O., Braga, F.O., Lima Júnior, É.P., and Monteiro, S.N., 2019, Curing kinetic parameters of epoxy composite reinforced with mallow fibers, Materials, 12 (23), 3939.

[42] Zhu, L., Wang, Z., Rahman, M.B., Shen, W., and Zhu, C., 2021, The curing kinetics of E-glass fiber/epoxy resin prepreg and the bending properties of its products, Materials, 14, 4673.

[43] Ferdosian, F., Yuan, Z., Anderson, M., and Xu, C.C., 2016, Thermal performance and thermal decomposition kinetics of lignin-based epoxy resins, J. Anal. Appl. Pyrolysis, 119, 124-132. 